СТАТЬИ

УДК 631.46:631.87

ФЕРМЕНТАТИВНАЯ АКТИВНОСТЬ ЧЕРНОЗЕМА ОБЫКНОВЕННОГО ПРИ РАЗЛОЖЕНИИ СОЛОМЫ В ПОЧВЕ

\author{
1,2Безуглова О.С., ${ }^{1}$ Наими О.И., ${ }^{1}$ Полиенко Е.А., ${ }^{1}$ Лыхман В.А., \\ 'Дубинина М.Н., ${ }^{1}$ Поволоцкая Ю.С., 'Патрикеев Е.С. \\ ${ }^{1}$ ФГБНУ «Федеральный Ростовский аграрный научный ичентр», Ростовская обл., n. Рассвет, \\ e-mail:o.naimi@mail.ru; \\ ${ }^{2}$ ФАОУ ВО «Южный федеральный университет», Ростов-на-Дону, е-mail: lola314@таil.ru
}

\begin{abstract}
В условиях лабораторного эксперимента изучалась ферментативная активность чернозема обыкновенного в процессе разложения внесенной в него соломы и влияние на нее гуминовых препаратов и компенсирующей дозы минерального азота. Эксперимент проводился в контролируемых условиях температуры и влажности, длился 12 месяцев и включал 4 варианта в трех повторностях. Цель работы - определить влияние внесения в почву гуминового препарата на ферментативную активность почвы и степень разложения соломы. Определяли ферменты из группы оксидаз и гидролаз: каталазу, инвертазу, фосфатазу. Степень разложения соломы контролировали по разложению целлюлозы. Показано, что внесение соломы в почву ведет к увеличению ее ферментативной активности. Обработка гуминовыми препаратами увеличивает скорость процессов разложения соломы и повышает биологическую активность почв, а внесение минерального азота дает дополнительное питание почвенным микроорганизмам, что увеличивает их активность в процессах биотрансформации растительных остатков. Выявлено существенное увеличение уровня ферментативной активности чернозема обыкновенного в варианте с обработкой модифицированным гуминовым препаратом BIO-Дон-15, обогащенным культурой Clostridium. Максимальных величин в этом варианте достигли активность каталазы - 12,3 мл О/ $/ 1$ мин и активность инвертазы - 27,8 мг глюкозы на 1 г почвы/24 ч. Процент разложения целлюлозы был максимальным в варианте с внесением компенсирующей дозы минерального азота $-74,2 \%$. Установлена положительная корреляция уровня инвертазной активности с содержанием гумуса в почве (коэффициент корреляции 0,67 ) и отрицательная - между активностью фосфатазы и содержанием подвижного фосфора (коэффициент корреляции - 0,80).
\end{abstract}

Ключевые слова: чернозем обыкновенный, солома, ферментативная активность, каталаза, инвертаза, фосфатаза, целлюлаза, гуминовые препараты

\title{
ENZYMATIC ACTIVITY OF ORDINARY BLACK EARTH DURING DECOMPOSITION OF STRAW IN THE SOIL
}

${ }^{1,2}$ Bezuglova O.S., ${ }^{1}$ Naimi O.I., ${ }^{1}$ Polienko E.A., ${ }^{1}$ Lykhman V.A., ${ }^{1}$ Dubinina M.N., ${ }^{1}$ Povolotskaya Yu.S., ${ }^{1}$ Patrikeev E.S.

${ }^{1}$ Federal Rostov Agricultural Research Center, Rostov Region, Rassvet, e-mail: o.naimi@mail.ru;

${ }^{2}$ Southern Federal University, Rostov-on-Don, e-mail: lola314@mail.ru

Enzymatic activity of black earth was studied within the process of decomposition of straw, introduced into the soil, as well as influence of humic preparations and a compensating dose of nitrogen under conditions of laboratory experiment. The experiment was conducted within controlled conditions of temperature and humidity, it lasted for 12 months and included 4 variants in three replicates. The objective of this work is to determine the effect of applying humic preparation upon enzymatic activity of the soil and degree of decomposition of straw. Enzymes from the group of oxidases and hydrolases were determined: catalase, invertase, phosphatase. Degree of decomposition of straw was controlled by the decomposition of cellulose. It is shown that the introduction of straw into the soil leads to an increase of its enzymatic activity. Treatment with humic preparations increases rate of decomposition of straw and increases biological activity of soils. Addition of mineral nitrogen gives additional nutrition to soil microorganisms, which increases their activity within biotransformation of plant residues. It was shown that treatment with modified humic preparation BIO-Don-15 with Clostridium culture significantly increased level of enzymatic activity of soil. The maximum values in this variant were registered for catalase activity $-12.3 \mathrm{ml}$ $\mathrm{O} 2 / 1 \mathrm{~min}$ and invertase activity $-27.8 \mathrm{mg}$ glucose per $1 \mathrm{~g}$ soil / $24 \mathrm{~h}$. Percentage of cellulose decomposition was maximal for the variant with mineral nitrogen $-74.2 \%$. A positive correlation was found between the invertase activity level and soil humus content (correlation coefficient 0.67 ) and negative correlation - between phosphatase activity and mobile phosphorus content (correlation coefficient - 0.80).

Keywords: black earth, straw, enzymatic activity, catalase, invertase, phosphatase, cellulase, humic preparations

Запашка соломы в почву является наиболее экологически приемлемым и эффективным способом утилизации побочной продукции растениеводства, при котором, в отличие от сжигания, не происходит загрязнения атмосферы окислами углерода и азота. Внесение в почву соломы и пожнивных остатков зерновых культур является реальным средством пополнения органического вещества в почвах агроценозов в условиях отрицательного баланса гумуса в земледелии. При этом повышается пло- 
дородие почвы, увеличивается ее биологическая активность, растет урожайность выращиваемых культур $[1,2]$. Однако применение соломы в качестве органического удобрения ограничивается низкой скоростью ее разложения в почве, что обусловлено широким соотношением содержания углерода и азота входящих в ее состав органических веществ - целлюлозы, лигнина и кремнийорганических соединений. При разложении соломы в почве создается дефицит минерального азота, могут выделяться фитотоксичные соединения и накапливаться фитопатогены [3, 4]. Для получения положительного эффекта от внесения соломы необходимо обеспечить условия для ускорения процессов ее разложения. Известно, что внесение 10 кг/т минерального азота обеспечивает активное функционирование микрофлоры, участвующей в биотрансформации соломы. Обработка соломы различными биологическими препаратами, в том числе гуминовыми, также позволяет ускорить процессы ее минерализации и гумификации [4-6].

Важнейшую роль в процессах разложения соломы и образования гумуса в почве играют природные биокатализаторы - ферменты. Почвенные ферменты представляют собой высокомолекулярные белковые вещества - продукты метаболизма почвенного биоценоза. Они образуются в результате жизнедеятельности почвенной мезо- и микрофауны, прижизненных растительных корневых выделений, а также поступают в почву после отмирания высших растений и почвенных организмов $[7,8]$. Ферментам свойственна высокая активность, которая сохраняется довольно продолжительное время, специфичность воздействия и зависимость от факторов внешней среды влажности почв, температуры, кислотности $(\mathrm{pH})$, химического и физического состава и т.д. [9].

Принимая участие в разложении остатков растений и микроорганизмов, синтезе и распаде гумуса, гидролизе органических соединений, ферменты могут быть индикаторами скорости разложения соломы в почве. В связи с этим целью нашей работы являлось изучение ферментативной активности чернозема обыкновенного в процессе разложении соломы в почве и влияние на нее обработки гуминовыми препаратами.

\section{Материалы и методы исследования}

Изучение ферментативной активности почв проводилось в условиях лабора- торного эксперимента. Почву - чернозем обыкновенный карбонатный - из пахотного слоя смешивали с соломой озимой пшеницы (из расчета 6 т/га), измельченной до 2-3 см, и компостировали при температуре 20$22^{\circ} \mathrm{C}$ и влажности почвы $60 \%$ от ПВ.

Опыт был заложен в трехкратной повторности и включал следующие варианты:

1 - почва + солома (контроль);

2 - почва + солома + гуминовый препарат ВIO-Дон;

3 - почва + солома + гуминовый препарат ВІО-Дон-15;

4 - почва + солома + минеральный азот (аммиачная селитра) из расчета 10 кг/т.

Обработка гуминовыми препаратами проводилась при закладке опыта. ВIO-Дон гуминовый препарат на основе вермикомпоста, содержит 2 г/л органического вещества гуминовых и фульвокислот. ВІО-Дон-15 модифицированный гуминовый препарат, обогащенный культурой Clostridium.

Образцы почв отбирались по истечении $1,3,5,7,9$ и 12 месяцев компостирования почвы с соломой. Активность каталазы, инвертазы и фосфатазы определяли методами А.Ш. Галстяна [9]. Для определения целлюлазной активности почвы был использован аппликационный метод [10]. Результаты обработаны методами статистического анализа с помощью программы Excel; в тексте статьи и на графиках приведены средние величины.

\section{Результаты исследования и их обсуждение}

Ферментативная активность является наиболее стабильным параметром среди показателей, характеризующих биологическую активность почв [11]. Ферментативный состав почв весьма разнообразен и существенно меняется в пространстве и во времени. Черноземы характеризуются достаточно высоким уровнем активности изучаемых ферментов [12, 13]. В данном исследовании биологическое состояние чернозема обыкновенного оценивалось по активности ферментов двух классов: окислительно-восстановительных или оксидоредуктаз (каталазы) и гидролитических или гидролаз (инвертазы, фосфатазы и целлюлазы), активность которых является важнейшим показателем биологической активности почв и оценки антропогенного воздействия на них.

Каталаза относится к классу оксидоредуктаз. Она разрушает токсичную для растений перекись водорода, которая обра- 
зуется в процессе их дыхания, в результате биохимических реакций окисления органических соединений и в процессе метаболизма аэробных организмов, в том числе целлюлозоразлагающих бактерий $[9,12]$.

Органическое вещество почв является одним из важнейших факторов, регулирующих активность каталазы в почве. Согласно работам некоторых авторов, активность каталазы возрастает при внесении соломы в почву, поскольку в процессе ее разложения увеличивается численность аэробной микрофлоры, образующих перекись в результате своей жизнедеятельности [5, 13]. Внесение соломы стимулирует протекание окислительно-восстановительных процессов в почве, что также оказывает влияние на активность каталазы.

До внесения соломы и обработки гуминовыми препаратами активность каталазы в черноземе в среднем составляла 7,9 мл $\mathrm{O}_{2} / 1$ г/1 мин. В течение пяти месяцев компостирования почвы с соломой активность каталазы увеличивалась по всем вариантам, однако почва остается в разряде среднеобеспеченных по шкале Звягинцева [11]. После семи месяцев компостирования темпы повышения активности каталазы возрастают и почвы переходят в категорию высокообогащенных. По всем срокам наблюдения активность каталазы была наименьшей в контрольном варианте. Внесение гуминовых препаратов и азота стимулирует активность каталазы, особенно в варианте 3, где применялся гуминовый препарат Віо-Дон-15. На этом варианте к концу опыта активность каталазы составила 12,3 мл $\mathrm{O}_{2} / 1$ мин, что превысило контроль на 0,7 мл, а вариант с минеральным азотом - на 0,2 мл (рис. 1).

За 12 месяцев компостирования активность каталазы на контроле увеличилась на $31,9 \%$, на вариантах с гуминовыми препаратами Віо-Дон и Віо-Дон-15 соответственно на $34,2 \%$ и $35,8 \%$, а на варианте с минеральным азотом - на 34,8\%.

Гидролазы представляют собой обширный класс широко распространенных в почвах ферментов. Они осуществляют реакции гидролиза высокомолекулярных органических соединений, действуя на различные связи (глюкозидные, пептидные, амидные) и играют важную роль в обогащении почв доступными питательными веществами $[4,9]$.

Инвертаза осуществляет гидролитическое расщепление сахарозы и ее производных по гликозидным связям до мономеров. Активность инвертазы определяется уровнем содержания органического вещества в почве и убывает по профилю, коррелируя с содержанием гумуса. Она в значительной степени отражает содержание в почве легкогидролизуемых углеводов, являющихся энергетическим материалом для многих почвенных гетеротрофов [11]. Некоторыми авторами отмечалась связь активности инвертазы с метаболической активностью почвенных микроорганизмов, что свидетельствует о преобладании в почве инвертазы микробного происхождения, однако активность инвертазы является более устойчивым показателем по сравнению с численностью микроорганизмов в почве, подверженной большим колебаниям [7].

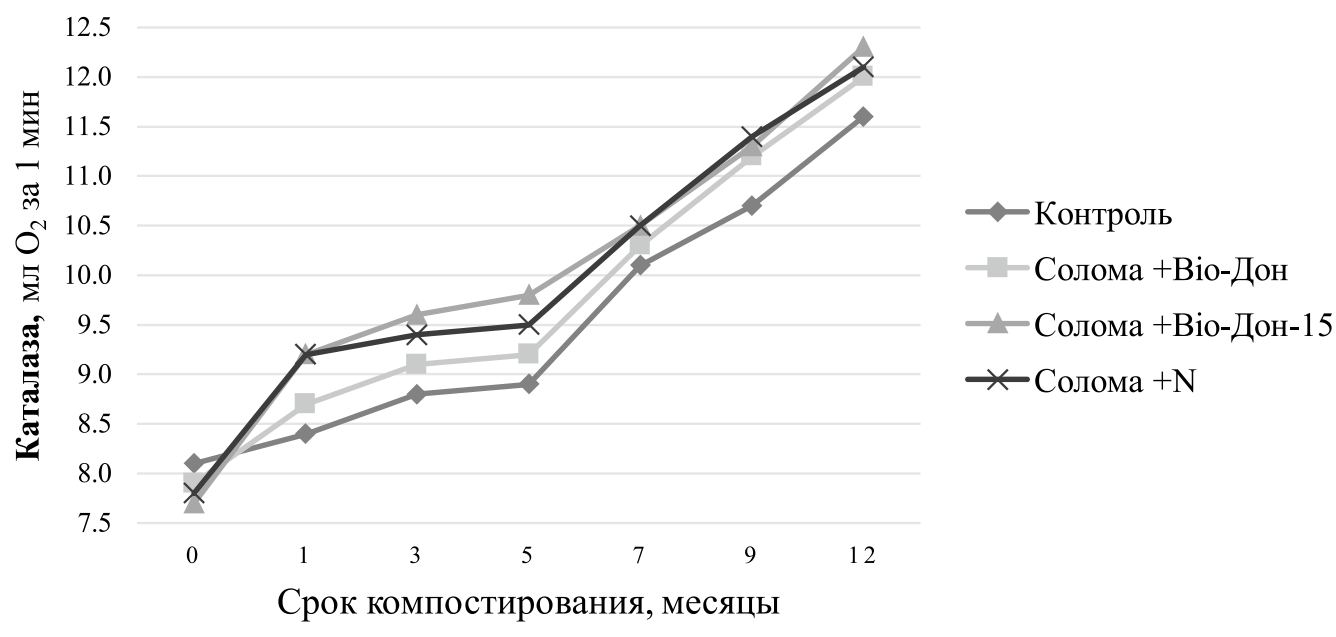

Рис. 1. Динамика активности каталазы в черноземе при разложении соломы 


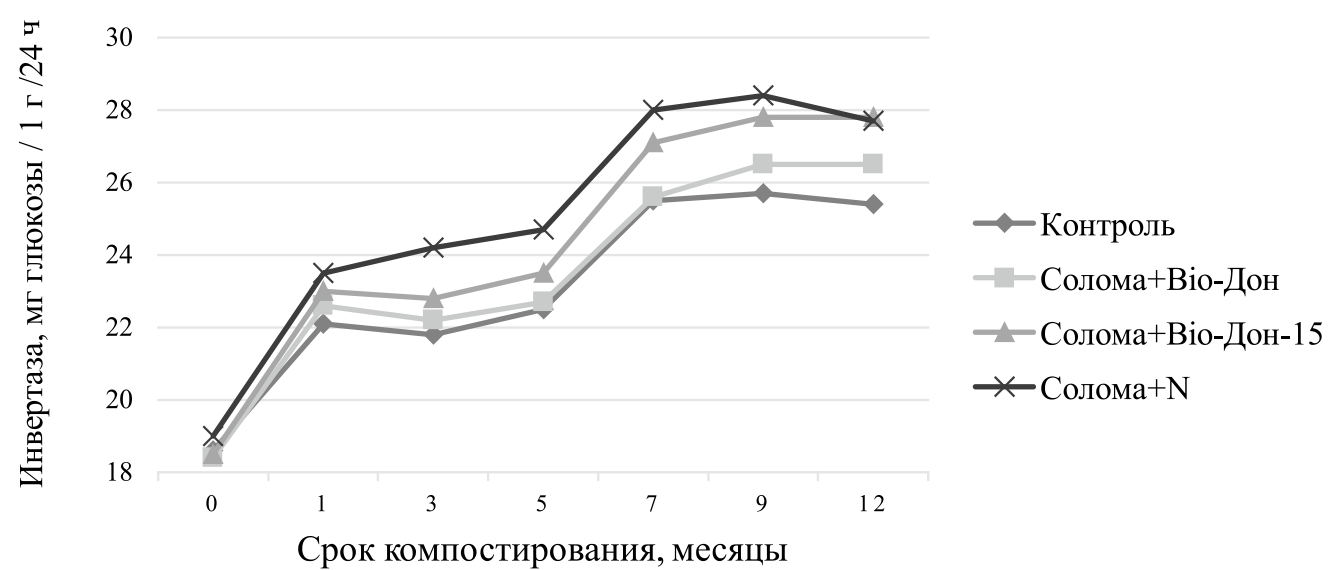

Рис. 2. Динамика активности инвертазы в черноземе при разложении соломь

Солома содержит большое количество углеводов и близких к ним соединений (до $60 \%$ от биомассы). Ее внесение в почву при благоприятном сочетании температуры и влажности стимулировало развитие пула гетеротрофных организмов и способствовало гидролизу легкодоступных углеводов, что выразилось в повышении инвертазной активности почвы. До внесения соломы уровень активности инвертазы в почве составлял в среднем 18,6 мг глюкозы на 1 г почвы за 24 ч. Через месяц компостирования активность инвертазы выросла во всех вариантах опыта. Наибольший рост наблюдался в вариантах 3 и $4-23,0$ и 23,5 мг глюкозы/1 г/24 ч соответственно (рис. 2).

После семи месяцев компостирования активность инвертазы резко возрастает, а с 7-го по 12-й - находится примерно на одном уровне, что говорит о том, что основная масса внесенной соломы уже «переработана» микроорганизмами (рис. 2). За весь период компостирования наибольший рост активности инвертазы наблюдался в вариантах с гуминовым препаратом BIO-Дон-15 и - на 33,5\%, тогда как в варианте с минеральным азотом рост активности составил $31,6 \%$, а на контроле $-26,8 \%$. Уровень инвертазной активности положительно коррелирует с содержанием гумуса в почве $(\mathrm{r}=0,67)$.

Фосфатаза отвечает за минерализацию органического фосфора, она катализирует гидролиз фосфорорганических соединений по фосфорно-эфирным связям, а активность фосфатазы характеризует интенсивность связанных с этим биохимических процессов. Этот фермент играет важную роль в обеспечении растений фосфором, высвобождая фосфорную кислоту из органических соединений, поступающих с растительными остатками $[7,9]$. При недостатке в почве доступного фосфора происходит дополнительное выделение ферментов микроорганизмами и растениями, что ведет к возрастанию фосфатазной активности. Справедливо и обратное утверждение при накоплении большого количества подвижного фосфора активность фосфатазы снижается.

Проведенные анализы показали, что в течение первого месяца эксперимента активность фосфатазы резко выросла на всех вариантах. Если до внесения соломы в почву она составляла в среднем 6,2 мг $\mathrm{P}_{2} \mathrm{O}_{5} / 100$ г почвы/1 ч, то через месяц она варьировала от 8,2 (на контроле) до 8,8 мг $\mathrm{P}_{2} \mathrm{O}_{5} / 100$ г почвы/1 ч (в варианте с внесением минерального азота). В варианте с обработкой препаратом ВIO-Дон-15 активность фосфатазы составила 8,6 мг $\mathrm{P}_{2} \mathrm{O}_{5} / 100$ г/1 ч, что превышает контрольный вариант на 0,4 мг. Затем в течение эксперимента активность фосфатазы снижалась к исходным позициям (рис. 3).

Снижение активности фосфатазы свидетельствует о накоплении доступного фосфора в почве. В результате проведенного корреляционно-регрессионного анализа установлено наличие достоверной обратной связи на достаточно высоком уровне значимости между активностью фосфатазы и содержанием подвижного фосфора $(\mathrm{r}=-0,80)$, что согласуется с исследованиями других авторов [9, 14]. 


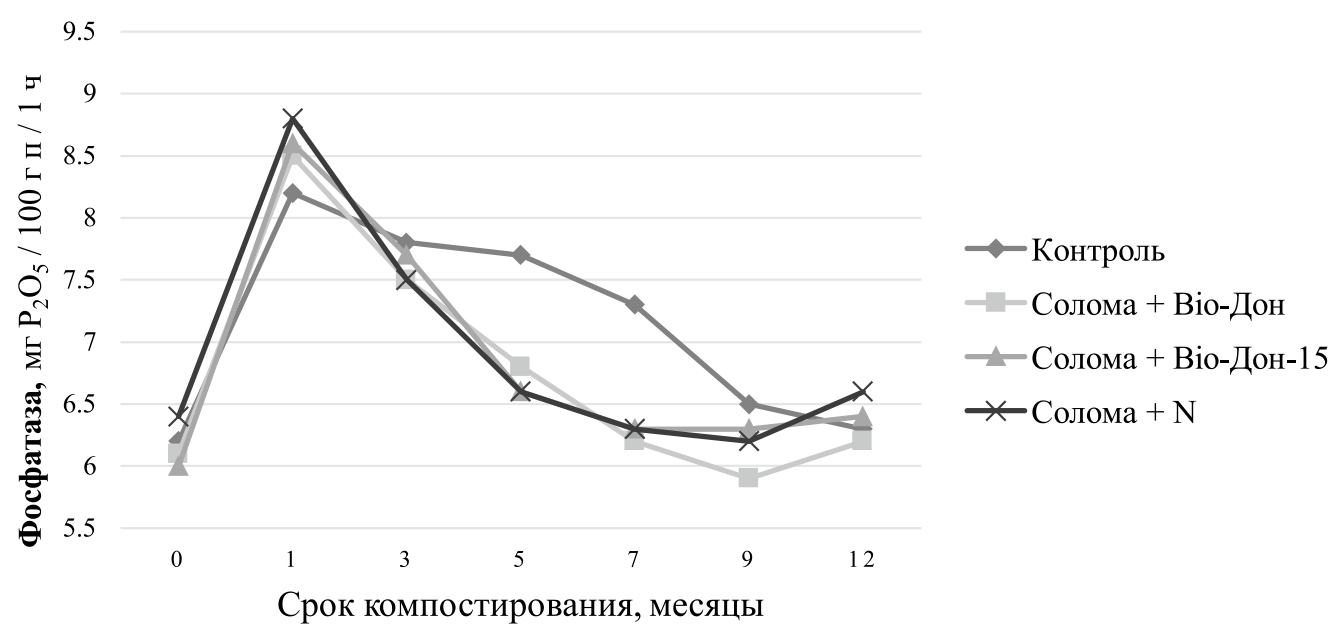

Рис. 3. Динамика активности фосфатазы в черноземе при разложении соломы

Целлюлоза является основной частью растительных организмов и представляет собой важный материал для гумификационных процессов. Содержание ее в растительных остатках достигает 50 и более процентов сухого вещества. Трансформация целлюлозы осуществляется группой микроорганизмов, способных продуцировать фермент целлюлаза. По прошествии двух месяцев с момента внесения раствора гуминовых препаратов «ВIO-Дон», «ВIО-Дон-15» и минерального азота мы наблюдали достаточно высокую степень разложения целлюлозы. Так, на контроле за два месяца разложилось $39,5 \%$ целлюлозы, что можно оценить как среднюю степень разложения по шкале Звягинцева [11]. Применение гуминового препарата ВIO-Дон стимулировало процесс разложения соломы, что отразилось на увеличении целлюлазной активности почвы до 45,2\%. Значительное увеличение степени разложения целлюлозы - до $65,9 \%$ - наблюдалось в варианте 3 с применением биопрепарата ВIO-Дон-15, что позволяет оценить интенсивность разрушения клетчатки на этом варианте как сильную. Однако целлюлазная активность на этом варианте все же ниже, чем на варианте с применением минерального азота $-74,2 \%$. Очевидно, внесение азотного удобрения создает более благоприятные условия для питания микроорганизмов, их усиленного развития и размножения и, как следствие, - повышения биологической активности почв.

\section{Заключение}

Активность каталазы постоянно растет на протяжении опыта и достигает максимальных величин в варианте с обработкой гуминовым препаратом BIOДон-15 - 12,3 мл $\mathrm{O}_{2} / 1$ мин.

Активность инвертазы имеет два периода с максимальными темпами роста - в первый месяц и 5-7 месяц компостирования почвы с соломой. За весь период компостирования наибольший рост активности инвертазы наблюдался в вариантах с гуминовым препаратом ВIO-Дон-15 - на 33,5 \%, тогда как в варианте с минеральным азотом рост активности составил $31,6 \%$, а на контроле - 26,8\%. Установлена положительная корреляция уровня инвертазной активности с содержанием гумуса в почве с коэффициентом корреляции 0,67 .

Активность фосфатазы резко возрастает в первый месяц компостирования, а затем снижается по мере накопления подвижного фосфора в почве. Между активностью фосфатазы и содержанием подвижного фосфора установлено наличие достоверной обратной связи на достаточно высоком уровне значимости $(\mathrm{r}=-0,80)$.

Процент разложения целлюлозы был максимальным в варианте с внесением компенсирующей дозы минерального азота $74,2 \%$ что превысило контроль на $34,7 \%$, а вариант с гуминовым препаратом ВIOДон-15 - на 8,3\%.

Таким образом, наши исследования экспериментально подтвердили, что внесение соломы в почву ведет к увеличению ее ферментативной активности. Внесение компенсирующей дозы минерального азота дает дополнительное питание почвенным микроорганизмам и повышает их активность в процессах биотрансформации 
соломы. Обработка соломы гуминовыми препаратами увеличивает скорость процессов ее разложения, что выражается в росте ферментативной активности почвы. Выявлено существенное увеличение уровня ферментативной активности чернозема обыкновенного в варианте с обработкой модифицированным гуминовым препаратом BIO-Дон-15, который сопоставим с таковым на варианте с внесением минерального азота.

\section{Список литературы / References}

1. Куликова А.Х., Яшин Е.А., Хисамова К.Ч. Влияние соломы яровой пшеницы на урожайность ячменя и баланс элементов питания в черноземе типичном// Агрохимия. 2017. № 3. C. 48-57.

Kulikova A.Kh., Yashin E.A., Khisamova K.Ch. The effect of spring wheat straw on barley productivity and the balance of nutrients in typical chernozem // Agrokhimiya. 2017. № 3. P. 48-57 (in Russian).

2. Зубарев Ю.Н., Фомин Д.С. Влияние основной обработки и заделки соломы в почву на засоренность и урожайность зерновых культур в звене «озимая рожь - ячмень овёс» в Предуралье // Аграрная наука Евро-Северо-Востока 2011. № 1 (20). C. 42-46.

Zubarev Yu.N., Fomin D.S. Influence of the basic processing of soil and заделки straw in soil on productivity and its structure in a link «a winter rye - barley - oats» in Predyralie // Agrarnaya nauka Yevro-Severo-Vostoka. 2011. № 1 (20). P. 42-46 (in Russian).

3. Наими О.И. Особенности использования соломы в качестве органического удобрения// Международный журнал гуманитарных и естественных наук. 2019. № 9-1. C. 10-13. DOI: 10.24411/2500-1000-2019-11552.

Naimi O.I. Features of the use of straw as an organic fertilizer // Mezhdunarodnyy zhurnal gumanitarnykh i yestestvennykh nauk. 2019. № 9-1. P. 10-13 (in Russian).

4. Еремин Д.И., Ахтямова А.А. Возможности ускорения разложения соломы яровой пшеницы в условиях лесостепной зоны Зауралья // Агропродовольственная политика России. 2015. № 4 (40). С. 35-38.

Eremin D.I., Akhtyamova A.A. Possibilities of decomposition of spring wheat straw accelerating in the conditions of the forest-steppe zone of the Trans-Urals // Agroprodovol'stvennaya politika Rossii. 2015. № 4 (40). P. 35-38 (in Russian).

5. Наими О.И., Безуглова О.С., Полиенко Е.А. Динамика ферментативной активности чернозема обыкновенного при внесении соломы // Здоровые почвы - гарант устойчивого развития: материалы научно-практ. конф. Курск, 2018. C. 73-77.

Naimi O.I., Bezuglova O.S., Polienko E.A. The dynamics of the enzymatic activity of ordinary chernozem when adding straw // Zdorovyye pochvy - garant ustoychivogo razvitiya: materialy nauchno-prakt. konf. Kursk, 2018. P. $73-77$ (in Russian).

6. Русакова И.В., Воробьев Н.И. Использование биопрепарата Баркон для инокулирования соломы, применя- емой в качестве удобрения // Достижения науки и техники АПК. 2011. № 8. С. 25-28.

Rusakova I.V., Vorob'ev N.I. Use biopreparation Barkon for inoculation of straw, applicable as fertilizers // Dostizheniya nauki i tekhniki APK. 2011. № 8. P. 25-28 (in Russian).

7. Звягинцев Д.Г. Иммобилизованные ферменты в почвах // Микробные метаболиты. М.: Изд. МГУ, 1979. C. $31-46$.

Zvyagintsev D.G. Immobilized Enzymes in Soils // Microbial Metabolites. M.: Izd. MGU, 1979. P. 31-46 (in Russian).

8. Наими О.И., Куцерубова О.Ю. Влияние антропогенных факторов на ферментативную активность чернозема обыкновенного // Пути повышения эффективности орошаемого земледелия. 2015. № 2 (58). С. 58-62.

Naimi O.I., Kucerubova O.Yu. The influence of anthropogenic factors on the enzymatic activity of ordinary chernozem // Puti povysheniya effektivnosti oroshayemogo zemledeliya. 2015. № 2 (58). P. 58-62 (in Russian).

9. Хазиев Ф.Х. Методы почвенной энзимологии. М.: Наука, 2005. 254 c.

Khaziev F.Kh. Methods of Soil Enzymology. M.: Nauka, 2005. 254 p. (in Russian).

10. Методы почвенной микробиологии и биохимии / Отв. ред. Звягинцев Д.Г. М.: Изд. МГУ, 1991. 304 с.

Methods of Soil Microbiology and Biochemistry / Otv. red. Zvyagintsev D.G. M.: Izd. MGU, 1991. 304 p. (in Russian).

11. Звягинцев Д.Г. Биологическая активность почв и шкалы для оценки некоторых ее показателей // Почвоведение. 1978. № 6. С. 48-54.

Zvyagintsev D.G. Biological activity of soils and scales for assessing some of its indicators // Soil Science. 1978. № 6. P. 48-54 (in Russian).

12. Наими О.И. Активность каталазы в черноземе обыкновенном и влияние на нее антропогенных факторов // Международный журнал гуманитарных и естественных наук. 2018. № 11-1. С. 12-15. DOI: 10.24411/2500-1000-2018-10142.

Naimi O.I. The catalase activity of the ordinary chernozem and effect of the anthropogenic factors on its level // Mezhdunarodnyy zhurnal gumanitarnykh i yestestvennykh nauk. 2018. № 11-1. P. 12-15 (in Russian).

13. Пилецкая О.А., Прокопчук В.Ф. Ферментативная активность черноземовидной почвы на фоне длительного применения удобрений // Вестник СВНЦ ДВО РАН. 2014. № 4. C. 41-45.

Piletskaya O.A., Prokopchuk V.F. Enzymatic activity of chernozem-like soil on the background of prolonged use of fertilizers // Vestnik SVNTS DVO RAN. 2014. № 4. P. 4145 (in Russian).

14. Куликова А.Х., Антонова С.А., Козлов А.В. Ферментативная активность почвы в зависимости от системы удобрения // Вестник Ульяновской государственной сельскохозяйственной академии. 2017. № 4 (40). С. 36-43. DOI: 10.18286/1816-45-2017-4-36-43.

Kulikova A.Kh., Antonova S.A., Kozlov A.V. Enzymatic activity of the soil depending on the fertilizer system // Vestnik Ul'yanovskoy gosudarstvennoy sel'skokhozyaystvennoy akademii. 2017. № 4 (40). P. 36-43 (in Russian). 